\title{
Ways of Knowing and Doing STS: Niki Vermeulen Talks with Wiebe Bijker
}

\author{
NIKI VERMEULEN \\ UNIVERSITY OF EDINBURGH \\ WIEBE BIJKER ${ }^{2}$ \\ NORWEGIAN UNIVERSITY OF SCIENCE AND TECHNOLOGY \\ AND MAASTRICHT UNIVERSITY
}

\begin{abstract}
It is a special moment in the history of STS. With the young discipline transitioning into a not soyoung-field-anymore, there is plenty of reason for celebrations: defining groups are celebrating remarkable anniversaries and individual careers are celebrated when founding figures retire. These celebrations are also excellent moments for reflections on pasts, presents and futures of STS and the place of STS in the wider world. In this conversation, Wiebe Bijker, recently subject of his own retirement celebration in Maastricht (Bijker 2017), shares his views on STS. We travel with him from the Netherlands to India, and briefly stop in Edinburgh at SSU where we find the origin of the SCOT abbreviation. On the way, we discuss Dutch activism, teaching, the institutionalization of STS, the emergence of international networks, and different roads STS can take. We end with an optimistic view towards a global future, while emphasizing the importance of the inclusion of history and the classics.
\end{abstract}

\section{Keywords}

STS; history; celebrations; bicycles; SCOT

\section{The Emergence of STS in the Netherlands: From Social movement to Institutionalization}

NV Starting with reflections of the origin of STS and the different fields that contributed. How did you become involved in STS and what is the general view you are having on how the field developed?

WB In the Netherlands there was a quite active movement--what we then called "science \& society" -involving mostly students and junior staff in engineering and natural science

. Niki Vermeulen, Email: niki.vermeulen@ed.ac.uk

.Wiebe Bijker, Email: w.bijker@maastrichtuniversity.nl

Copyright (c) 2018 (Niki Vermeulen, Wiebe Bijker). Licensed under the Creative Commons Attribution Non-commercial No Derivatives (by-nc-nd). Available at estsjournal.org. 
departments. They were concerned about the role of the military in university research, and quite active in discussions in the Netherlands about the nuclear arms race and disarmament, and particularly nuclear power. As a student I was part of that movement and I think that for the Netherlands this was the beginning of STS, or at least an important starting point. An interesting additional step which I think is quite unique-I don't know of any other country where something like that happened--is that the Ministry of Education, Culture and Science thought that it might be valuable to have a more professional, dedicated expertise on the role of science in society. They therefore announced a competition to draft a research program for what was then called a "science dynamics program." Four universities participated. The winner would receive a professorial chair, but each of the participants got 100,000 guilders, about 50,000 euros now, to prepare for that competition. Only one of the four universities won-and that was Amsterdam, so in Amsterdam the chair of science dynamics was established, on which Stuart Blume was then appointed. However, the actual investment of 4 times 100,000 guilders basically meant an investment in the whole field in the Netherlands. And although the four universities competed, we still kept--in a Dutch spirit-quite friendly with each other, so that even after Amsterdam was granted the chair the four universities continued to collaborate. In a way this competition was, after the science \& society movement, a second and more formal step to create a presence of STS in the universities. So I would sketch the origin of STS in the Netherlands in these two steps.

NV Next to Amsterdam, the other place was Twente I suppose?

WB Yes, and then the other two were Groningen, in the north of the Netherlands, and Leiden. Arie Rip was in Leiden then, although after the competition Arie moved relatively soon to Amsterdam when he also got a chair in the science dynamics group. And then those were the three Dutch STS centers: Groningen, Amsterdam and Twente.

NV So these Dutch developments were then embedded in kind of a broader international development? Or perhaps parallel to similar developments in the UK and the US, and probably France?

WB I think that in those early years there was little international interaction, with the exception of Arie, and of course Stuart Blume who came from the UK. The field was not yet very academically oriented, but much more directed towards politics and policy.

NV In terms of time we are talking about the beginning of the 70s isn't it?

WB No, this is already the end of the 70s. I can't recall exactly when, this competition must have been around 1981-82.

NV So the movement was in the 70s and then this kind of competition, institutionalization took place in the beginning of the 80s?

WB Yes, exactly. 


\section{The Creation of International Networks in STS}

NV How did you become aware that the development in the Netherlands were part of a broader movement that was later called STS?

WB That was very much a personal contingency. In 1980 I was appointed as a junior researcher in Twente University and as part of that project I went to my very first international conference, and that happened to be the very first EASST meeting: the meeting in which EASST was formally established, in Graz in Austria. There I was to present, together with Ellen van Oost, the first preliminary results of our project on what would become the Social Construction of Technology. However, our department had a bit of extra money and they wanted to use that extra money to bring some foreign scholar for half a year to Twente: they asked us to keep an eye open for any possible candidate that we might meet in Graz. Then Ellen and I bumped into Trevor Pinch. We actually didn't know him and I had never heard of him, but our first meeting went off quite well, we liked him and he liked our work. His postdoc contract in Bath was ending by the end of that calendar year and he would be unemployed by 1 January. So that seemed a very nice fit. I went back to the university, reported about Trevor, Trevor was invited, Trevor came, and that opened my eyes to the international STS, or more precisely the SSK community. We made the link through Trevor with Harry Collins and then I presented Trevor's and my work in Paris, where I met David Bloor from Edinburgh but also Michel Callon and Bruno Latour. That is how my connection to the international STS community started, and I think that at that moment Arie and I were the only ones who had such international connections, although from then onwards it rapidly grew.

NV What is your idea about how these people came together basically before you knew them?

WB I hesitate to call it a community, but my sense is that in the UK back then, most of the people of my generation all knew each other: John Law, Harry Collins, David Edge, David Bloor, Barry Barnes, Donald MacKenzie, and Mike Mulkay. John Law had done his $\mathrm{PhD}$ in Edinburgh so they knew each other, they had partly studied with each other and then the link with Bruno came, I think mostly through Steve Woolgar, and then there was the very first $4 S$ meeting in Cornell in 1975. That was long before I was part of academic STS; in those days I taught physics in secondary school, and wrote physics textbooks with an STS twist. The field already had, I suppose one can say, started around the establishment of the journal Social Studies of Science in Edinburgh with David Edge and Roy MacLeod in Australia. But I was blissfully unaware of all that when it happened.

NV That's also interesting that there's different kinds of countries and groups that then at one point come together, there's obviously a specific pattern of emergence in that sense.

WB There's one other interesting link that I had to one part of the international STS community, particularly in Britain, and that was along a very different line and that happened already in the late 1970s: this was because of my involvement (just mentioned) 
in innovating science teaching and in trying to incorporate more science \& society issues in secondary school teaching.

NV A kind of Responsible Research Innovation at high school level.

WB Through that channel I met John Ziman and his partner Joan Solomon, but also David Edge. David was very interested in those kinds of issues, including teaching at secondary schools, although he didn't do it himself; he was thinking about how to innovate science teaching also in secondary schools. I vividly remember that we sat next to each other-it was an extremely nervous experience for me-we sat next to each other in a pretty small workshop at the Free University in Amsterdam, completely focused on secondary school science teaching, and science in society teaching. Trevor and I had just sent our SCOT article to him to be reviewed about two or three weeks earlier. So I was sort of paralyzed and thought: if I don't say anything he'll wonder later when he opens that letter what that guy next to him was doing, but if I say something I may be violating rules about the communication between an author and an editor? At some point I did introduce myself, David was of course his very amicable and comforting self, and it all went well.

\section{The Edinburgh School and the Origin of SCOT}

NV So in that sense Edinburgh was already a little bit known to you?

WB Yes.

NV What in general are your memories of this group and how do you see its importance in the field, in its emergence and also maybe in its development.

WB I think the importance of Edinburgh can't be overstated. First because of David Edge and Social Studies of Science. But also because of the work by David Bloor, Barry Barnes and Donald MacKenzie in helping to create SSK and thus being foundational for everything that we do now. So I would say that there was Edinburgh with those key names and then there was the Bath school with particularly Harry Collins but also Trevor, and then there were Mike Mulkay, Steve Woolgar, John Law, Andy Pickering, Steven Yearley, Malcolm Ashmore, and I may be forgetting a few.

NV Do you remember when you went to Edinburgh for the first time?

WB Years later. I don't remember when exactly, but much later than all this happening. I think I've only been there once and perhaps visited David in his office, I seem to have a memory of a rainy day in Edinburgh. So I have visited Edinburgh probably only once. It doesn't feel like that because I keep meeting the Edinburgh people everywhere and we've had quite intensive contacts without my being there physically.

NV And the role of the Strong Program?

WB That was extremely important, and it has been very important for my own work. I still explain SCOT by reference to the Strong Program. Even apart from SCOT, some of the central themes of the Strong Program are crucial pedagogical tools to explain some of the core ideas of constructivist science studies to students. So, even if you don't want to train 
them narrowly within the Strong Program, just using the Strong Program is pedagogically very effective I think.

NV Do you have a concrete example?

WB I know that I have this little book by Barry Barnes that has many pencil notes by me in the margin. But also David Bloor's work on symmetry is particularly important for me. I regularly use Donald's work on the Pearson correlation coefficient as an example of the role of interests in shaping scientific knowledge. And in the early days of SCOT, interacting with Donald and Judy Wajcman about their edited volume Social Shaping of Technology was important too.

NV Yes, because that's a book where you have the different perspectives coming together as I remember quite well.

WB In this context it's probably also worth noting that actually the name of SCOT was invented by David Edge. He told Trevor and me, that if you are writing this article balancing EPOR-the Empirical Program of Relativism-and your own work on technology, you'll need an acronym to combine with EPOR. What about SCOT? Of course who could refuse any suggestion by David, and definitely one like this? So it is his invention, and considering how adamant a Scot he was himself, we giggled a bit and then happily followed his suggestion.

\section{Transformations in STS}

NV Moving on from the foundation of STS to its further development, how do you see STS having changed over time?

WB I can't oversee the complete 50 years of the Unit but in the last 40 years one important development, and I participated in that, is that the domain of social studies of science was broadened to also include technology, also include medicine, and it keeps expanding. Current work in Edinburgh is very much contributing to that. Secondly. I mentioned that in the Netherlands STS started as a politically motivated movement more than as a scholarly research tradition within academia. I now see internationally, including what I know about the current program in Edinburgh, that there is increasing sensitivity to normative and political issues, including explicit engagement with policy questions but also more theoretical and philosophical attention to normative questions. You just mentioned Responsible Research Innovation (RRI), I think STS can pride itself on having had a clear influence on the shaping of that RRI agenda in Europe. So for the Netherlands that means a sort of coming full circle, back to the political agenda with which STS started out. For most scholars in the UK it did not start out as a political approach: SSK very much started as an academic project in mostly the sociology of science, and only later was related to political questions, for example with Harry Collins' and Robert Evans' Third Wave paper. The third development is extending STS beyond the northern and western hemispheres. There again Edinburgh is crucial in its collaboration with Chinese scholars and doing research in China. This third development 
is a bit more recent than the other two, but quite substantive and, I think, very important for the future.

NV These three developments that are visible in Edinburgh and in the Netherlands, are these also most important through the history of STS more generally?

WB Yes, absolutely. You just need to browse the programs of the $4 S$ and EASST annual meetings to recognize these three trends. There have been explicit discussions to change the name of $4 \mathrm{~S}$, to include technology and medicine. I'm quite happy that we didn't do that because you cannot continue to extend it by listing every next domain that STS investigates. The meeting programs show how much attention to political and policy issues is now being paid. And there is a very increased membership from the global south and east; and $4 \mathrm{~S}$ had meetings in Tokyo and Buenos Aires.

\section{Interdisciplinary Relations}

NV Going back to the underlying disciplines that STS is resting on-history, sociology and philosophy of science; and also of course the sciences, as many first generation scholars had a background in natural sciences-how do you see the relation of STS to other disciplines in the broader academic community?

WB I think a description of the history in terms of disciplines is actually quite interesting because I think in Britain and in Edinburgh it was only sociology and philosophy, but philosophy with a sociological twist. That was different in the Netherlands, where philosophy of science played a substantive role. While in the UK much of the work was formulated in opposition to philosophy of science, this was not the case in the Netherlands. In the Netherlands we had some collaboration with historians but not very much. In the UK Steve Shapin and Simon Schaffer created an important bridge to history of science, while in the Netherlands historians came mostly in via technology studies. I don't think that in the Netherlands or the UK there was any explicit anthropology of science, previous to Laboratory Life by Bruno Latour and Steve Woolgar. Since then economics and policy studies became more important. I consider SPRU an STS center, but some don't. There is an increasing number of scholars in organizational sociology active in drawing on STS and also contributing back to STS. Particularly with RRI (Responsible Research and Innovation) the link to philosophy got re-established. So the spectrum of disciplines is really much broader and richer now than it was in the 1970s, though of course with different profiles in different centers and countries.

NV I was also wondering about the connection between history and sociology of science. In the Netherlands they seem quite close together, while in the UK these seem to be more separate communities. For instance in Maastricht historians and sociologists are working together, and I didn't experience a barrier that I couldn't cross. Then I was thinking your work has also been switching between the two, so what are your thoughts on this?

WB It helps to distinguish between history of science and history of technology. History of science in most countries is quite established, it's the longest and also richest tradition- 
also richest money-wise- but often also the most conservative of the three. In the US, for example, first only the History of Science Society (HSS) existed, and then the Society for the History of Technology (SHOT) broke away from HSS because the founders of SHOT (then all members of HSS) felt that in HSS attention to technology was underrated and that there wasn't enough space for innovative historical research. I think that the link between social studies of science and technology and SHOT is the closest one, and in centers like Maastricht, Cornell and MIT, historians of technology and sociologists of science and technology belong to one department. My interactions with the SHOT are rewarding. Although many historians still have their doubts about social theory and what they (often rightly) consider unnecessary jargon, they do recognize the fruitfulness of a social constructivist approach. I think that the gap between social and historical studies of technology will become increasingly smaller and I hope the same will happen with the history and sociology of science. Something that happened only two weeks ago which was extremely nice was that I was invited by the Dutch Graduate School in Classics-Greek and Latin studies and history, political philosophy, literature, archaeology of ancient Greece and Rome. They had discovered SCOT and want to build their research program around innovation in the Roman-Greco culture 2,000 years ago around constructivist approach to innovation.

NV SCOT going back to the classics?

WB It is fascinating that classicists start using SCOT, and I expect this collaboration to be beneficial for a better understanding of current innovation and technical change too. What is much more regularly happening is that practitioners-of all kinds: engineers, nanoscientists, development interventionists, handloom activists-find STS, and especially SCOT, useful because they better understand the relations between science, technology and society that they operate in on a daily basis. Because SCOT, with its relevant social groups and idea of interpretive flexibility, stays relatively close to what many practitioners can imagine and see happening around them. I meet many people outside academia - or in academia but definitely outside regular STS units--who find SCOT useful for their teaching or the political intervening work that they do.

NV That's interesting because ANT has spread, for instance, to conservation studies and art history. And you see similarly SCOT crossing boundaries between academia and practice. What would you see as other important disciplines where STS is, or needs to be interacting with more? What are other kind of interfaces?

WB I would find it difficult to think of any discipline that could not benefit from collaborating with STS. That sounds like an arrogant statement, but what I mean is that I think that for any discipline it helps to take a kind of a constructivist turn, not in a very strict and ideological sense, but just a slightly different way of looking at one's own practice and at the practices that are the object of study. My recent work on clinical trials is an example. The malaria researchers with whom I did this research (published in Social Studies of Science, 2016; my daughter Else is the first author) found it very insightful to use a constructivist STS perspective on their work. I benefited much myself, 
because we were able to formulate theoretical ideas about trust-control tandems that, we claim, are crucial in all knowledge construction processes. Secondly I think that the STS practice of collaborating across disciplinary boundaries is increasingly asked from any researcher in any discipline, so that also in that sense anyone could learn from STS. Until two weeks ago I might have excepted classics from this statement...So, I cannot think of any discipline that could not benefit from a little dose of STS.

\section{Going Back to the Classics}

NV And the other way around, STS needing to learn from other disciplines, what would you say?

WB I think, but that's partly reflecting my personal failings, that STS would really benefit from revisiting some of the classic social science and philosophy theorists. I think that revisiting the Webers, Durkheims and Deweys of this world, which is all happening now, is a very worthwhile project. Even Merton: in the 1980s, SSK and STS did develop very much in antagonism to Mertonian sociology of science. But we are way beyond that fight now, and revisiting someone like Robert Merton is extremely fruitful.

NV Ok, so that's in some ways going back to the roots and reinterpreting them from our current perspective. With Merton this would be about norms in science?

WB Yes, but also his empirical work, his sociological empirical work about the role of science in society. I still teach his norms of science, of course with the additional footnote that it doesn't empirically describe what has actually going on. These norms are worth thinking about it, if only to teach these students a certain ethical self-awareness of what scientists should and should not do. Merton has done much valuable sociology work that is not directly about science. Let's put it like this: I think STS is now so strong and mature that they don't need to be afraid to go back to some of those stalwarts whom it criticized in the early days.

\section{Different Ways of Doing STS}

NV Yes, that's an interesting perspective. Does this not apply to the academic detour that you have identified for Dutch STS? Of course you said already that it is one of the central trends that there is more engagements with politics and policy taking place now, but how do you see the relation to policy studies and political sciences?

WB I think that is happening indeed. I saw three parallel routes: the policy street and the academic highway and the STS boulevard. These still exist in parallel to each other and I would make a plea that big research centers would do well to have a portfolio that includes activities in all three, as a group. Individuals may be more comfortable in only one of the three, but it would be beneficial for research and teaching of a center to have activities in all three. I think all three routes have grown enormously in strength and in capacity over the past 15 years. The policy street is very clear with all the consultancy 
and policy-related work that many STS people do part of their time, whether it is in a high-level experts group in Brussels or certain European projects that have a more consultancy taste than academic taste. The academic highway is pretty clear with all the research schools, the postgraduate programs, undergraduate programs. Trevor and I always call STS an emerging discipline. We do call it a discipline, but still emerging because we don't want to get completely bogged down in the disciplinary pillars. And I think that the STS boulevard is visible in what we talked about previously: that much of the research that you see happening in EASST and 4 S conferences does have a mix of empirical work, theoretical work and societal inspiration with sensitivity to normative and political issues. Many projects have all three elements, and may foreground one or the other, depending on the context.

\section{The Future of STS: Links with Science and Global Perspectives}

NV That nicely leads to the last part of our conversation, where do you see STS going when you say "it has all the characteristics of a discipline"? How do you see the future of STS? Because we are at a point where groups exists 50 years and many people will be retiring quite soon?

WB Well, I think the future is pretty bright: programs like Horizon 2020 make a strong plea to include responsible research and innovation (RRI), important bodies like the European Commission or the Health Council of the Netherlands explicitly invite STS people for advisory roles, we have high-quality research schools, and students are coming in... Though "worry" is too negative, I would like us to think about the effect that many STS graduates now do not have a science degree. With the big success and the consolidation of bachelor and master programs, current graduates typically do not have the same background in science as the older generation have. Now, people like yourself have been trained in social sciences or humanities, then turned to STS and start studying science and technology. We need to make sure that also with that new generation of researchers, who don't have that engineering or science in their blood, the relationships with the science and engineering disciplines are maintained and made productive. Someone like you does that very well, but it is more difficult for you than it was for me. I can quite cheaply play that cards of, "I am a physicist" or "I am an engineer," and you cannot do that.

NV I can see that. But you do also see some programs that are now trying to return to that original position and educate people with a science background to have a major or minor in STS. In addition, what do you see missing from STS at the moment, that isn't done and needs to be done? Is there anything particular that you're immediately thinking of?

WB To be honest, no. I see important and big issues and problems that need to be addressed, but I see researchers who start doing that. I think that the kind of work that is done in Edinburgh in collaboration with Chinese colleagues and on China, and the work that I'm doing with Indian colleagues and on India, was missing until some ten years ago. The 
skewed orientation on the North and the West that STS had in its early decades is being addressed now; it's still missing in a sense that there isn't enough of that research, but it's not missing in the sense that it is a blind spot that people don't recognize.

NV But of course there is a whole world to explore out there.

WB Yes, absolutely. And I think most of the benefits are still to be harvested in say the next ten years.

NV The final question is: what excites you the most about what is going on in STS at the moment that you see as promising?

WB What excites me most is having this Chinese student who also worked as an intern in Edinburgh last year and who had no clue about STS but ended up in our research master because he did understand what we were trying to do and he was fascinated. But we had to sort of turn him around, not only from his Chinese background to also understanding a European northern perspective, but from being a communication science person to an STS person, teaching him how to do fieldwork. The other example is the work that I am doing in India, which really makes me rethink what knowledge is, what science is, how people relate to each other, what is ethically allowed and also effective as forms of intervention if you want to improve livelihoods of people or the stability of a society. I think I am learning more in India within a year than I did in the ten years before in Europe, and I wouldn't be surprised if that happens to Robin Williams going to China too.

NV Yes, we have started some work with Korea recently too.

WB There is a strong community in East Asia: Korea, Taiwan, Japan, China, Singapore. The Society for History of Technology 2016 meeting will be in Singapore. And there is increasing STS activity in Latin America too: Brazil, Argentina, Colombia.

\title{
Learning STS: From Student to Interviewer Multiple
}

\author{
BY NIKI VERMEULEN
}

Let me start these reflections by telling you that this was actually the second time I interviewed Wiebe Bijker. The first time was 2010, during the Society for Social Studies of Science (4S) conference in Japan. It was hot and humid on the campus of the University of Tokyo, it was the final conference day, and there was a camera with Wes Shrum behind it. Being part of a series of interviews with past presidents of $4 \mathrm{~S}$, Wiebe talked about the emergence of STS and the role of $4 \mathrm{~S}$, but also about his own career and his contributions, including the development of the Social Construction of Technology (SCOT) theory. This is also the reason why this time around, we did 
not focus too much on Wiebe's own career, as this is already covered by that former interview which can be found on the $4 S$ website (http://www.4sonline.org/past_officers). So, why was I asked to interview Wiebe twice?

The first time Wes asked me to conduct the interview because Wiebe was my $\mathrm{PhD}$ supervisor. In fact, I know Wiebe from my undergraduate studies onwards, and he is one of the reasons I became interested in STS. The course he designed on the "Maakbaarheid" of the Netherlands-a term that simply does not translate in English but which for this purpose I will translate as the social construction of the Netherlands-made me decide to follow a specialization in "Technological Culture." I especially remember the field trip to the Dutch Delta works, where Wiebe showed us around together with his father Eco Bijker, who worked as an engineer on those impressive Delta works. In a later course designed around Wiebe's inaugural lecture on "The Democratisation of Technological Culture" these Delta works figured again, as an example of a technology that was the result of political deliberations. The Oosterschelde storm surge barrier is the result of a compromise between different social and political visions, as the technology incorporates both the desire to protect the land from flooding and the wish to keep the landscape behind the barrier as it was: with the tide going in and out, preserving the local salty water culture of mussels and fishing. While Wiebe's courses were among the best during my university education, little did I know that the specialization in "Technological Culture" was actually a synonym for STS, and that Wiebe was one of the field's founding figures. I slowly figured all that out during my years as a graduate student.

My lectureship in Edinburgh forms the reason I was asked to interview Wiebe a second time around. My new colleagues, the editors of this project, asked me to participate and matched me with Wiebe again. I almost forgot to conduct the interview in English instead of Dutch, but luckily Wiebe reminded me. On a few occasions we both struggled to find the appropriate word in English, so a big thank you to all involved in the transcription and editing process for keeping up with our Dutchisms.

An obvious point of discussion was the connection between Edinburgh and Maastricht. It turned out that Wiebe had travelled to Edinburgh only once, and for me that was definitely the most shocking revelation of the interview. I am still a bit puzzled about why this was the case. He said something about rain, but in my experience it does not rain in Edinburgh more often then it does in Maastricht, although it is quite a bit colder in summer. Next to the weather, I have been thinking about different schools of thought, slightly different generations, and meetings taking place during conferences in other places around the world. At least that is how I keep in touch with Wiebe and the Dutch: going to $4 S$ or the European Association for the Study of Science and Technology (EASST) meetings, as this is the best place to catch up with the whole Dutch STS community. However, most notably the connection between Wiebe and Edinburgh is the SCOT theory, which, as Wiebe explained, was an acronym suggested by David Edge for obvious reasons. Perhaps in some ways this makes Wiebe part of the Edinburgh School.

Most importantly, I am glad that STS has started to do some history of its own field. This interviews project clearly contributes to that, and I have already heard about other projects too (see for instance the interview with Arie Rip in this series). Looking back at our own history 
seems something inevitable for a community that studies the way in which academic communities emerge and transform. Also, I think it is a valuable resource for people that are new to STS, and the present generation of scholars that were not part of its history.

Personally, I found it particularly interesting to hear about the role of different people, and disciplinary communities in the emergence of STS. When recalling the early days, Wiebe recounts the step-by-step, person-by-person growth of the field. He discusses encounters with scholars at particular meetings, and in doing so learning about other centers and setting up important collaborations. For example, he mentions meeting Trevor Pinch at a meeting in Graz, and the subsequent partnership that developed when Pinch came to work in the Netherlands. He also discusses meeting Edge, David Bloor, Harry Collins, Michel Callon, and Bruno Latour at different moments. Each of these meetings furthered the growth of the community in some ways, and contributed to Wiebe's personal development as a scholar. A crucial part of this was the disciplinary contributions brought by each person. For instance, he mentions that Latour brought anthropological sensitivities. As such, the interdisciplinary character of STS becomes especially visible through its early history.

Within this context, it was especially clarifying for me to learn how Wiebe experienced the relationship between sociology and history of science/technology. As in my own research I am trying to bridge the two, this relationship has been an important thread running through my career. More specifically, and although in my own education there was no real barrier between the two approaches, I discovered after leaving Maastricht that in other places and countries there are both intellectual and institutional barriers that can be quite persistent. Especially in the United Kingdom, I found that the history of science and the STS community are quite distinct, with their own conferences and networks that do not necessarily overlap, and only in a few places. One of these places is the Manchester Centre for the History of Science, Technology and Medicine (CHSTM), where the late John Pickstone was very much in favor of trying to connect the two communities and especially the two ways of understanding the development of science. My work has benefitted enormously from his generous support and part of his intellectual agenda is also visible in Edinburgh, as there are important connections between the two places, and as Edinburgh's Science Technology and Innovation Studies aims to connect both history and STS in its research agenda, together with innovation research.

As such, the question arises: why do those barriers exist? Exploring the history of the disciplinary configurations of STS proves to be a way towards a better understanding of these boundaries and their resilience, while perhaps also opening-up new possibilities to bridge.

Finally, and next to Wiebe's optimism about the future of STS, I would like to stress the importance of his suggestion to return to classic authors. Wiebe argues that as someone without formal training in the social sciences, doing so has been useful, but he also argues that doing so can help newer generations of STS researchers, which include a majority of people trained in the social sciences, humanities, and STS. Very importantly, he frames this turn to classic authors as something that STS can do now because it has established itself enough, it is mature enough. It also balances the future-oriented character of STS and the many new ideas and concepts that 
emerge, with a revisiting of older concepts, and perhaps discovering new knowledge and understandings through old ideas.

As such, Wiebe's contribution can be read as a challenge to the STS community and its future agenda. A challenge that can be formulated as a challenge to boundaries. Boundaries between various disciplines (e.g. history of science/technology and STS), between academic STS and politically engaged STS, between "the West and the rest," between old concepts and new concepts, and between past and present, in order to build a future. In any case, I am looking forward to interviewing Wiebe in another five years time again, as part of our emerging "Five Up" series. To be continued...

\section{Author Biography}

Niki Vermeulen is senior lecturer/associate professor in history and sociology of science in Science, Technology and Innovation Studies (former SSU) of the University of Edinburgh, and a visiting researcher at the Centre for Science and Technology Studies (CWTS) of the University of Leiden. Her work focusses on ways of organizing research, especially collaboration in the life sciences and biomedicine. She completed her PhD at Maastricht University with Wiebe Bijker, and her academic journeys took her subsequently to the Science and Technology Studies Unit (SATSU) of the University of York, the Department of the Social Studies of Science of the University of Vienna, and the Centre for the History of Science, Technology and Medicine (CHSTM) of the University of Manchester. In addition, she worked as a science policy advisor/consultant, e.g. for Technopolis Group. Niki is a member of the Royal Society of Edinburgh's Young Academy of Scotland and has recently developed virtual walking tours through Edinburgh www.curiousedinburgh.org for which she won the Tam Dalyell Prize.

\section{Author Biography}

Wiebe E. Bijker (1951) is Professor of Technology \& Society at the Norwegian University of Science and Technology, Trondheim, and professor emeritus at Maastricht University, The Netherlands. Educated as an engineer (physics) at Delft University, he studied philosophy of science at the Universities of Amsterdam and Groningen, and received a PhD in the history and sociology of technology from Twente University. He played a central role in designing the teaching programme of the Netherlands Graduate School of Science, Technology and Modern Culture (WTMC), in establishing the European MA programme European Society, Science and Technology studies (ESST), and the research master Cultures of Arts, Science and Technology (CAST) of Maastricht University. Bijker held a variety of administrative offices in Maastricht University, nationally, and internationally. Internationally his Presidency of the Society for Social Studies of Science and various roles in the Society for the History of Technology stand out. His engagement between academic work and the practices of science and technology becomes apparent in his work for the Health Council of the Netherlands, the Rathenau Institute, the research council NWOIWOTRO Science for Global Development, and the Knowledge in Civil 
Society Forum (KICS, Hyderabad, India). Bijker received the John Desmond Bernal Prize (2006), became Officier in de Orde van Oranje Nassau (2009), and was awarded the Leonardo da Vinci Medal by the Society for the History of Technology (2012).

\section{References}

Bijker, W. 2017. “Constructing Worlds: Reflections on Science, Technology and Democracy (and a Plea for Bold Modesty)." Engaging Science, Technology, and Society, Vol. 3., p. 315-331. Doi:10.17351/ests2017.170. 